\title{
Mechanical Thrombectomy in the Treatment of Distal Occlusions during Coil Embolization of Ruptured Intracranial Aneurysms
}

\author{
Francesco Briganti, ${ }^{1}$ Giuseppe Leone, ${ }^{2}$ Mariano Marseglia, ${ }^{2}$ Carmela Chiaramonte, ${ }^{3}$ Domenico Solari, ${ }^{3}$ \\ Ferdinando Caranci, ${ }^{2}$ Paolo Cappabianca, ${ }^{3}$ and Francesco Maiuri ${ }^{3}$
}

\begin{abstract}
The experience in the management of thromboembolic complications of distal vessels during coil embolization using stent-retrievers in the setting of subarachnoid hemorrhage $(\mathrm{SAH})$ is still limited. We report a case of 58-yearold woman with a ruptured small anterior communicating aneurysm who experienced during coil embolization a thromboembolic occlusion of the upper post-bifurcation branch of the middle cerebral artery. Mechanical thrombectomy with a stent-retriever (Solitaire, Covidien, Neurovascular) resulted in complete recanalization of the occluded branch with no ischemic complication. This case should encourage the use of the Solitaire device as an effective rescue strategy in the treatment of distal artery occlusions in the setting of SAH.
\end{abstract}

Keywords: intracranial aneurysms, brain aneurysm, subarachnoid hemorrhage, coiling, stent-retriever, solitaire

\section{Introduction}

There is a growing evidence for the efficacy of mechanical thrombectomy with stent-retrievers in acute stroke patients from large-vessel occlusion in the anterior circulation. ${ }^{1)}$ On the other hand, the experience of this technique in the management of thromboembolic complications of distal vessels during coil embolization for ruptured intracranial aneurysms is still limited.

We report a case of a successful treatment with mechanical thrombectomy using a stent-retriever in a patient who experienced thromboembolic occlusion of the upper post-bifurcation branch of the left middle cerebral artery (MCA) during coil embolization of a small anterior communicating aneurysm.

\section{Case Report}

A 58-year-old woman was admitted to our Institution for sudden headache and loss of consciousness. At the neurological exam, she was classified as Hunt \& Hess grade 2.

CT scan and CTA showed subarachnoid hemorrhage (SAH) with ventricular diffusion and a small anterior communicating

${ }^{1}$ Unit of Interventional Neuroradiology, Department of Advanced Biomedical Sciences, "Federico II" University, Naples, Italy

${ }^{2}$ Department of Advanced Biomedical Sciences, "Federico II" University, Naples, Italy

${ }^{3}$ Division of Neurosurgery, Department of Neurosciences, Reproductive and Odontostomatological Sciences, "Federico II" University, Naples, Italy

Received: January 26, 2016; Accepted: March 17, 2016 aneurysm (ACoA) (6 mm) (Fig. 1). Thus, the endovascular aneurysm occlusion with coils was planned in the same procedure. After the placement of a 6F guiding catheter (Envoy, Cordis, Miami Lakes, Fla) into the left internal carotid artery (ICA), a microcatheter (Echelon 10, Covidien/ev3 Inc, Irvine, CA) was advanced through the guiding catheter and placed into the aneurysm sac. A heparinized saline solution was continuously perfused through the guiding and the Echelon microcatheter during the procedure. At the end, the aneurysm was completely occluded with five coils in 25 minutes.

However, after the microcatheter removal, angiograms from the guiding catheter showed occlusion of the upper post-bifurcation branch of the left MCA (Fig. 2A).

Local intra-arterial fibrinolysis with urokinase, abciximab, or recombinant tissue plasminogen activator was excluded, because of the SAH. Thus mechanical thrombectomy with a stent-retriever (Solitaire $3 \times 20 \mathrm{~mm}$, Covidien, Neurovascular) was decided.

The $6 \mathrm{~F}$ vascular sheath was replaced by triaxial system (NeuronMax 088, Penumbra, Alameda, CA, USA; LIR 5.5, Phenox, Bochum, Germany). The upper bifurcation branch of the left MCA was navigated with a 0.014-inch Silverspeed microwire (Covidien/ev3 Inc, Irvine, CA) and a 0.018-inch Rebar microcatheter (Covidien/ev3 Inc, Irvine, CA). The stent-retriever (Solitaire $3 \times 20 \mathrm{~mm}$ ) was deployed by the withdrawal of the microcatheter and fully opened in the occluded branch.

Within 3 minutes the open stent-retriever was withdrawn back into the intermediate catheter under continuous aspiration using a $20 \mathrm{ml}$ syringe. A clot was evidenced in the retriever. Control angiograms showed complete recanalization of the occluded branch of the MCA (Fig. 2B).

$\mathrm{CT}$ scan at the end of the procedure, at 36 and 72 hours and 3-month MR showed no ischemic or hemorrhagic events (Fig. 3).

Low-molecular-weight heparin (5000 IU/daily) was administered during the next days.

A triventicular hydrocephalus was evidenced at 72 hours, and it was successfully treated by external ventricular drainage.

The patient was discharged 10 days after the procedure without clinical deficits $(\mathrm{mRs}=0)$.

\section{Discussion}

Acute intraprocedural thrombosis complicates $5-10 \%$ of endovascular treatments of coiling for cerebral aneurysms. ${ }^{2}$ 

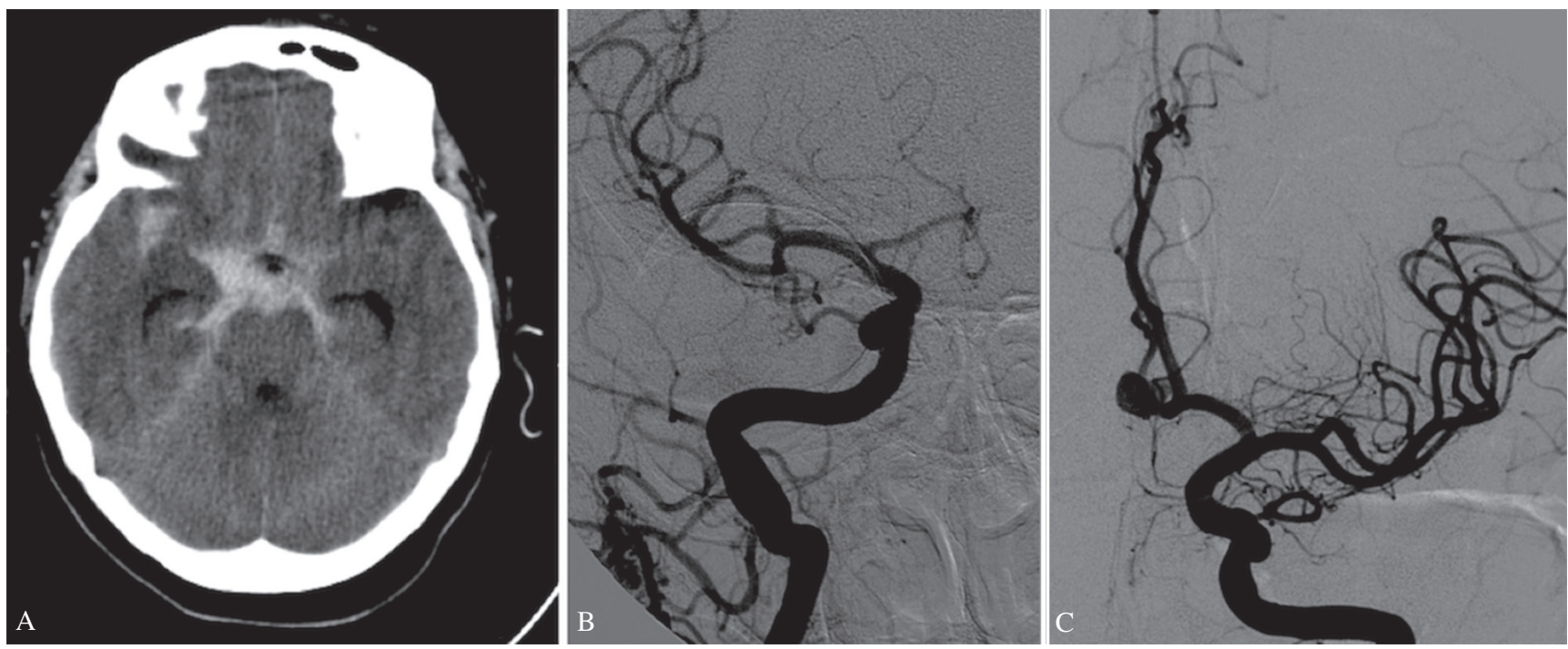

Fig. 1 CT obtained by a 58-year old woman presenting with diffuse subarachnoid hemorrhage (Fisher 3). (A) Digital Subtraction Angiography showed small anterior communicating aneurysm (AcoA) $(6 \mathrm{~mm})$, hypoplasia of right A1 and both A2 tracts of the anterior cerebral artery (ACA) arising from the left $\mathrm{A} 1(\mathrm{~B}, \mathrm{C})$.
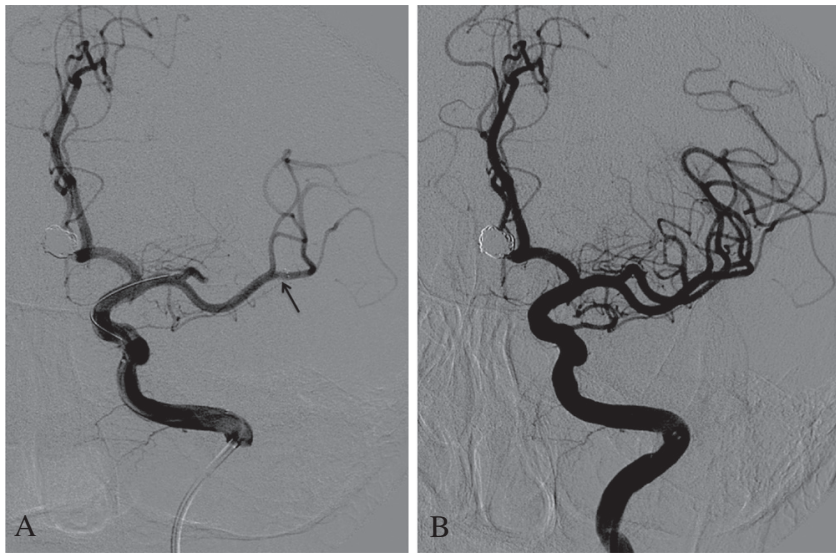

Fig. 2 Stent-retriever deployment: the radio-opaque marker of the Solitaire $(3 \times 20 \mathrm{~mm})$ is labeled $(\mathrm{A})$; the angiogram after the retrievement showed complete recanalization of the left M1 MCA upper branch (B).

In a large series of ruptured aneurysms, ${ }^{3)}$ thromboembolic complications occurred in $4.7 \%$, accounting for $1.9 \%$ mortality and $2.8 \%$ morbidity.

In spite of the heparinization, both systemic and through the guiding and microcatheter, embolic events can occur during the coil treatment for several sources; they include damage of friable plaques, iatrogenic dissection, air bubbles, and thrombus or fresh clots within the aneurysm and catheters. ${ }^{4)}$

In the occurrence of intraprocedural thrombosis, the local intra-arterial fibrinolysis with urokinase, abciximab, or recombinant tissue plasminogen activator may help to recanalize the occluded artery but the even complete recanalization does not prevent a major neurological deficit. However, in the setting of SAH from ruptured aneurysms the management of thrombotic complications may be difficult and must balance between maintaining intra-aneurysmal occlusion and lysis of the thrombus in the occluded artery.
Although it has been demonstrated that rescue therapy with GpIIb/IIIa inhibitors is associated with significantly better outcome in both ruptured and unruptured aneurysms, ${ }^{5}$ they are not easily reversed, resulting in increased hemorrhagic risk.

We have decided in our patient the mechanical thrombectomy with a stent-retriever with the aims to reduce the risk of bleeding and prevent severe ischemic deficits.

Although this approach is often not considered in patients with acute occlusion of the MCA branches distal to the bifurcation, in this case it was possible to safely access the embolus, because it was located in an artery different and distal from the territory of the aneurysm. In fact, when the thrombus occurs in the same arterial territory of the aneurysm, thrombectomy with the stent-retriever can be a challenge. While its deployment may easily be performed, its withdrawal is dangerous; the retraction force of the stent-retriever combined with the aspiration by the intermediate catheter can mobilize the coils with occlusion of the parent vessel. Detachment of the device has been proposed, but it was associated with higher rates of symptomatic intracranial hemorrhage, poorer outcome, and higher mortality rate at 90 days. ${ }^{6}$ Thus, we do not recommend the stent-retriever technique in these cases.

The thrombus aspiration is another possible strategy. In a multicenter study ${ }^{7)}$ the direct aspiration first-pass (ADAPT) technique has recently been shown to achieve a high recanalization rate $(78 \%)$ in ischemic stroke, similar to the stentretrievers. ${ }^{7}$ The direct thrombus aspiration without the necessity to pass through the occlusion and the possibility of using adjunctive devices, such as stent-retrievers are the main advantages of this technique. For distal occlusions, as in our case, the stent-retriever alone is in our opinion the recommended option.

Although the clinical experience is still initial, the thrombectomy using stent-retrievers in distal occlusions is a welltolerated treatment. Sheth et al. reported no difference in TICI $2 \mathrm{~b} / 3$ recanalization rates in occlusions beyond M1 compared 

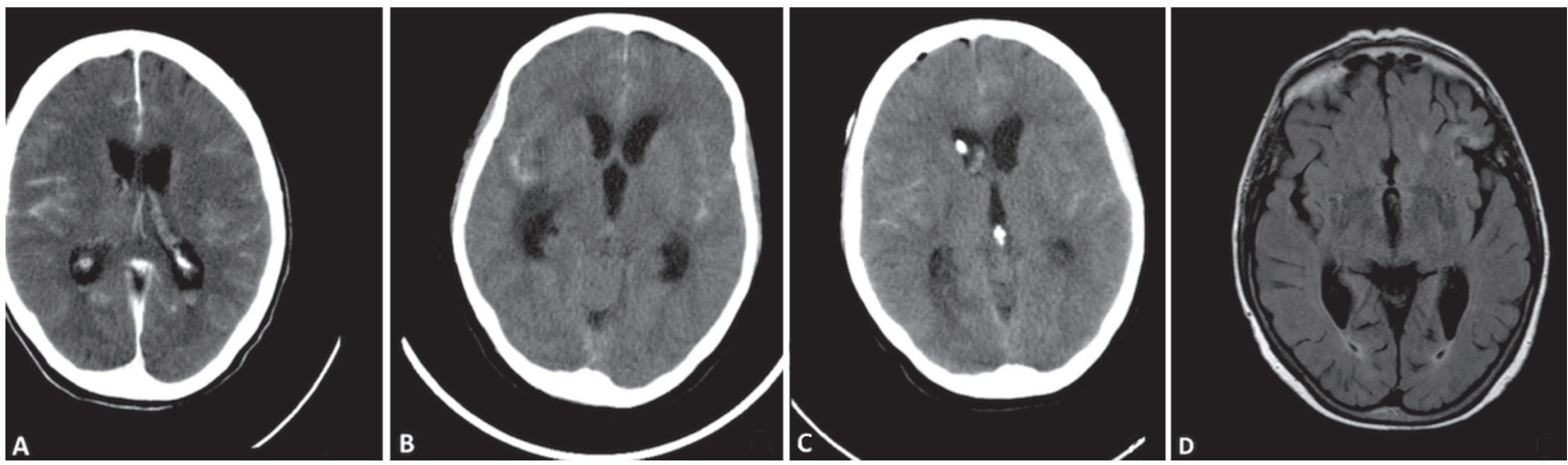

Fig. 3 CT scan at the end of the procedure (A), at $36(\mathrm{~B})$ and $72(\mathrm{C})$ hours showed no ischemic or hemorrhagic events. MR (D) axial T $\mathrm{T}_{2} \mathrm{~W}$ FLAIR at 3 -month confirmed no ischemic events.

to $\mathrm{M} 1$ ones and smaller final infarcts, decreased infarct expansion, and improved clinical outcomes. ${ }^{8)}$ Flores et al..$^{9}$ reported in patients with distal occlusions good recanalization rate $(78.5 \%)$ associated with dramatic improvement, smaller infarct volumes and better outcome; they showed that this treatment may double the chances of favourable outcome. Finally, Dorn et al. ${ }^{10)}$ report greater chance of good angiographic and clinical results in distal MCA occlusions than in M1 ones.

In our patient we achieved the complete recanalization of the upper post-bifurcation branch of the left MCA with no new ischemic or hemorrhagic events and good clinical and neurological outcome.

\section{Conclusion}

The experience with this case should encourage the use of mechanical thrombectomy with a stent-retriever device for thromboembolic occlusions in the setting of SAH.

This technique should also be recommended for thromboembolic complications of distal vessels (as beyond the M1 segment) where it results in better clinical and neurological outcome, avoiding the need of intra-arterial or systemic fibrinolysis.

\section{Disclosure Statement}

Francesco Briganti serves as a proctor for Covidien.

The other authors have no conflict of interests.

\section{References}

1) Berkhemer OA, Fransen PS, Beumer D, van den Berg LA, Lingsma HF, Yoo AJ, Schonewille WJ, Vos JA, Nederkoorn PJ, Wermer MJ, van Walderveen MA, Staals J, Hofmeijer J, van Oostayen JA, Lycklama à Nijeholt GJ, Boiten J, Brouwer PA, Emmer BJ, de Bruijn SF, van Dijk LC, Kappelle LJ, Lo RH, van Dijk EJ, de Vries J, de Kort PL, van Rooij WJ, van den Berg JS, van Hasselt BA, Aerden LA, Dallinga RJ, Visser MC, Bot JC, Vroomen PC, Eshghi O, Schreuder TH, Heijboer RJ, Keizer K, Tielbeek AV, den Hertog HM, Gerrits DG, van den Berg-Vos RM, Karas GB, Steyerberg EW, Flach HZ, Marquering HA, Sprengers ME, Jenniskens SF, Beenen LF, van den Berg R, Koudstaal PJ, van
Zwam WH, Roos YB, van der Lugt A, van Oostenbrugge RJ, Majoie CB, Dippel DW: MR CLEAN Investigators. A randomized trial of intraarterial treatment for acute ischemic stroke. N Engl J Med 2015; 372: 11-20. Erratum in: N Engl J Med 22: 372-394, 2015

2) Pelz DM, Lownie SP, Fox AJ: Thromboembolic events associated with the treatment of cerebral aneurysms with Guglielmi detachable coils. Am J Neuroradiol 19: 1541-1547, 1998

3) van Rooij WJ, Sluzewski M, Beute GN, Nijssen PC. Procedural complications of coiling of ruptured intracranial aneurysms: incidence and risk factors in a consecutive series of 681 patients. Am J Neuroradiol 27: 1498-1501, 2006

4) Rordorf G, Bellon RJ, Budzik RE Jr, Farkas J, Reinking GF, Pergolizzi RS, Ezzeddine M, Norbash AM, Gonzalez RG, Putman CM: Silent thromboemoblic events associated with the treatment of unruptured cerebral aneurysms by use of Guglielmi detachable coils: prospective study applying diffusion-weighted imaging. Am J Neuroradiol 22: 5-10, 2001

5) Brinjikji W, Morales-Valero SF, Murad MH, Cloft HJ, Kallmes DF: Rescue treatment of thromboembolic complications during endovascular treatment of cerebral aneurysms. Stroke 44: 1343-1347, 2013

6) Castaño C, Dorado L, Remollo S, García-Bermejo P, Gomis M, Pérez de la Ossa N, Millán M, García-Sort MR, Hidalgo C, López-Cancio E, Cubells C, Dávalos A: Unwanted detachment of the Solitaire device during mechanical thrombectomy in acute ischemic stroke. J Neurointerv Surg Jan 27. pii: neurintsurg-2015-012156, 2016

7) Turk AS, Frei D, Fiorella D, Mocco J, Baxter B, Siddiqui A, Spiotta A, Mokin M, Dewan M, Quarfordt S, Battenhouse H, Turner R, Chaudry I: ADAPT FAST study: a direct aspiration first pass technique for acute stroke thrombectomy. J Neurointerv Surg 6: 260-264, 2014

8) Sheth SA, Yoo B, Saver JL, Starkman S, Ali LK, Kim D, Gonzalez NR, Jahan R, Tateshima S, Duckwiler G, Vinuela F, Liebeskind DS: UCLA Comprehensive Stroke Center. M2 occlusions as targets for endovascular therapy: comprehensive analysis of diffusion/perfusion MRI, angiography, and clinical outcomes. J Neurointerv Surg 7: 478483, 2015

9) Flores A, Tomasello A, Cardona P, de Miquel MA, Gomis M, Garcia Bermejo P, Obach V, Urra X, Martí-Fàbregas J, Cánovas D, Roquer J, Abilleira S, Ribó M: Catalan Stroke Code and Reperfusion Consortium Cat-SCR. Endovascular treatment for M2 occlusions in the era of stentrievers: a descriptive multicenter experience. J Neurointerv Surg 7: 234-237, 2015

10) Dorn F, Lockau H, Stetefeld H, Kabbasch C, Kraus B, Dohmen C, Henning T, Mpotsaris A, Liebig T: Mechanical thrombectomy of M2 occlusion. J Stroke Cerebrovasc Dis May 4. pii: S1052-3057(15)00206-2 2015

Corresponding author:

Francesco Briganti, Department of Advanced Biomedical Sciences, Unit of Interventional Neuroradiology, Federico II University, Naples, Italy.

$\triangle$ frabriga@unina.it 